\title{
Perspectives of female leaders on sense of coherence and mental health in an engineering environment
}

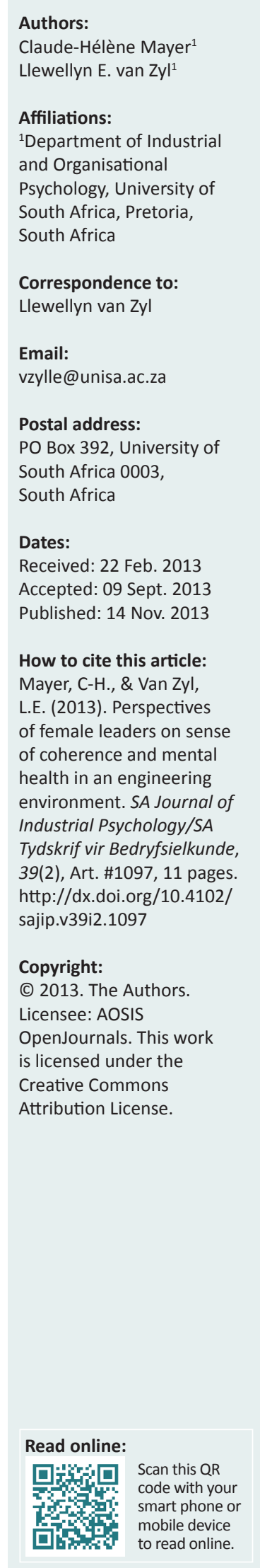

Orientation: Positive organisational behaviour impacts strongly on various individual and work-related outcomes. Gender perspectives in this paradigm have not yet been comprehensively researched.

Research purpose: This article explores female perspectives on mental health and sense of coherence. The aim is to promote an understanding of gender-related subjective perceptions on mental health and sense of coherence from an emic perspective.

Motivation for the study: Limited research exists regarding the perceptions of positive leadership behaviour of female leaders within South African who experience unique challenges within the business environment and remain healthy at the same time.

Research design, approach and method: Data from a mixed-method research study are presented, thereby providing insights into quantitative and in-depth qualitative empirical data from 15 female leaders. The study followed a single, embedded case study approach.

Main findings: The main findings show that sense of coherence, mental health and gender awareness are connected. Female leaders with a high sense of coherence refer to gender in a positive or neutral way in a male-dominated work environment. The results emphasise individual and social health-promoting strategies in an organisation and the way personal life orientation contributes to individual (mental) health.

Practical/managerial implications: Organisations need to focus more on promoting mental health in terms of gender and gender-related positive psychology frames.

Contribution/value-add: This study contributes to the literature on gender within the positive organisational behaviour paradigm, presents recommendations for future research and highlights the practical implications for organisations.

\section{Introduction}

Over the past decade, research on positive organisational behaviour has increased steadily (Luthans, 2002a) and the importance of positive psychological concepts in organisational settings has been highlighted (Seligman, 2011; Seligman \& Csikszentimihalyi, 2000). The focus of organisational research on understanding positive affect, behaviours and cognitions has gained interest in national and international contexts (Donaldson \& Ko, 2010; Rothmann \& Rothmann, 2010; Van Zyl, Deacon \& Rothmann, 2010; Van Zyl \& Stander, 2013).

Positive organisational behaviour is understood as: 'the study and application of positively oriented human resource strength and psychological capacities that can be measured, developed, and effectively managed for performance improvement in today's workplace' (Luthans, 2002b, p. 59). Research has shown that emphasising positive organisational behaviour impacts strongly on individual and group-related behaviours in organisations (Lyubomirsky, 2013; Mendes \& Stander, 2011; Seligman, 2011). Since 2002, there has been an increase in research dealing with diversity issues and positive organisational behaviour, distinguishing between positive findings in diversity research and positive approaches to studying diversity (Ramarajan \& Thomas, 2010). However, most of the research over the past five decades highlights the fact that: 'researchers may not believe that positive and diversity can be studied together' (Ramarajan \& Thomas, 2010, p. 22). This might be a result of major inequalities relating to race, gender and other major categories existing in organisational contexts (Chugh \& Brief, 2008; Lyubomirsky, 2013). However, a number of organisational studies have researched behaviour pertaining to race (Thomas, 2001), cultural diversity (Thomas, 2004) and minorities (Thomas \& Gabarro, 1999) from a positive organisational behaviour perspective.

Similarly, gender, as a relevant category of diversity in organisations, has been increasingly investigated, based on the increasing numbers of women in organisations and the changing 
relationships between gender, work and society (Lawthom, 1999). However, gender studies have often been related to negative organisational behaviour such as job insecurity (Rosenblatt, Talmud \& Ruvio, 1999), stress and burnout (Oplatka, 2002). Similarly, some studies have specifically compared male and female organisational behaviour in terms of differences and inequalities (e.g. Eagly, JohannesenSchmit \& Van Engen, 2003) instead of in terms of positive organisational behaviour and equalities (Seligman, 2011).

Gender and health in organisations have often been studied in relation to differences in gender (Carless, 1998), comparisons of differences in (mental) health of gender classes (Sachs-Ericson \& Ciarlo, 2010), gender and dysfunctional organisational behaviour, as well as understanding gender challenges, work-life balance and the glass ceiling effect (Baxter, 2012; Bez \& Emhan, 2011). Additionally, gender and mental health are often researched in clinical contexts in relation to psychopathology (Afifi, 2007; Bez \& Emhan, 2011; Maddux \& Winstead, 2011). Only recently has the increase in the number of females taking up leadership positions in organisations been discussed (Amanatullah \& Morris, 2010; Baxter, 2012) and has there been a focus on the need for organisations to cope with growing complexities and new challenges such as managing meaningfulness (Wrzesniewski, 2003), work-related well-being (Wrzesniewski \& Tosti, 2005; Wrzesniewski, Dutton \& Debebe, 2003) and their organisational environment (Mayer, 2008; Seligman, 2011).

This new and dynamic situation calls for positive organisational approaches and concepts (Luthans, 2002b) in terms of developing and improving mental health and wellbeing in organisations (Luthans, 2002a; Van Zyl \& Rothmann, 2012; Van Zyl \& Stander, 2013; Youssef \& Luthans, 2007). Effective coping, high levels of sense of a coherence and well-being impact positively on job performance and life satisfaction as well as negatively when they are not fulfilled (Grant \& Campbell, 2007). Research on health is thus of vital importance in positive organisational behaviour research (Donaldson \& Ko, 2010). However, health and well-being as concepts of positive organisational behaviour have rarely been researched in terms of gender (Macik-Frey, Quick, Quick \& Nelson, 2009) and a void has been highlighted (Sandelands, 2002; Seligman, 2011), particularly in the South African context (Mayer, 2011).

Based on the aforementioned research problem, the aim of this article is to assess the perspectives of female leaders on (creating) mental health and experiencing a sense of coherence in a selected South African organisation. It attempts to demonstrate female perspectives on positive organisational behaviour in terms of mental health and sense of coherence in the South African management context and thereby promote a deeper understanding of gender-related subjective perceptions on (positive) organisational behaviour. In effect, this study aimed to address the following research questions:

1. How do female leaders in the selected organisation score in sense of coherence?

2. How do female leaders define their 'life orientation'?
3. How are mental health and gender connected in the eyes of the female leaders?

4. What strategies do female leaders suggest contribute to positive organisational behaviour in terms of constructing 'healthy organisations'?

\section{Literature review}

Mental health and well-being in organisations: The constitution of the World Health Organisation (WHO, 1948) defines health as a state of complete physical, mental and social well-being and not merely the absence of disease or infirmity. With regard to the occupational context, health promotion and maintenance of the highest degree of physical, mental and social well-being of workers across diverse occupations are promoted, working conditions and health risks are explored and physiological and psychological needs and capabilities are researched (Stellman, 1998, p. 28). Often, research regarding occupational health still mainly relates to men and male employees and has not yet addressed gender-specific conditions (Ruiz-Cantero et al., 2007). Mayer and Boness (2011a) highlight that definitions in health research often include physical, social and psychological (mental) dimensions. In this article, health is defined as a comprehensive concept, including the emotional, intellectual, spiritual, occupational, social and physical dimensions of individuals as whole persons (Davies, Davies \& Heacock, 2003).

The interest in concepts and topics of health and well-being in organisations has increased in South African organisations (Mendes \& Stander, 2011; Pillay, 2008; Van Zyl \& Rothmann, 2012). Of particular interest are international organisations investing in South Africa and how they react to the new demands on health services in organisations (Mayer, Louw \& Louw, 2010). In organisations in the South African context, international enterprises maintain a relatively high standard of healthy working conditions in comparison with small and medium-sized enterprises (South African Department of Labour, 2004). Health and well-being research is still mainly connected to research on negative concepts such as stress, burnout and disengagement and managerial health and wellbeing have received less attention in comparison (Legare \& Gelman, 2009). However, it has often been argued that health knowledge and promotion in organisations should be increased (Brinkmann, 1993). The contemporary view is that personal and organisational resources and perceptions of general health and well-being can support health promotion in organisations (Geißler, Bokenheide, Geißler-Gruber, Schlunkes \& Rinninsland, 2003). There is thus a renewed interest in understanding the psychological underpinnings of general health and well-being as developed in recent years (Rothmann \& Rothmann, 2010).

Health and well-being in the South African context: Health and well-being research in South African organisations has also gained major interest in positive organisational behaviour research (Mayer \& Boness, 2009), and the question of 'what keeps people healthy?' (Antonovsky, 1979) has 
gained popularity (e.g. Rothmann \& Cilliers, 2007). However, the Occupational Health and Safety Act's (South Africa, 1993) conceptualisation of general health is still in contrast to the understanding of health in major literary findings over the past two decades. According to the Act, health is defined as: 'being free from illness or injury attributable to occupational causes'. This definition re-emphasises the arguments of the disease model, in which health is defined in terms of the absence from illness and psychopathology (Seligman, 2011).

Authors of previous articles (e.g. Barkhuizen \& Rothmann, 2004; Rothmann \& Rothmann, 2010; Van Zyl et al., 2010) have highlighted various outcomes related to health and well-being that have become major issues in South African organisations. One of these outcomes is a sense of coherence. Sense of coherence, as a major life orientation, has been defined as a mediator between job stress and work wellbeing (Rothmann, Steyn \& Mostert, 2005). Rothmann et al. (2005) argue that sense of coherence acts as a mediating mechanism for various individual well-being and organisational performance variables. Sense of coherence activates unconscious and conscious mechanisms associated with higher stress tolerance, lower levels of burnout and disengagement, as well as leads to higher levels of selfefficacy and sustainable changes in the experience of positive affect (Mayer, 2011). Research further suggests that a high level of sense of coherence acts as a buffer for the onset of physical illnesses such as influenza (Rothmann et al., 2005). Similarly, Donaldson and Ko (2010, p. 183) conclude that 'well-being at work can bring several benefits to organisations and employees'.

Gender in organisations: Gender is defined as socially determined norms and roles for each sex (WHO, 2003). The phrase 'gender and health' is often used synonymously with 'women and health' (WHO, 2003, p. 2) and researchers have struggled to differentiate between 'gender' and 'female' (Alvesson \& Billing, 1992). Focusing on gender in selected areas of organisational behaviour, it has been emphasised that women's leadership is on the rise (Eagly \& Carli, 2003) but that more female leaders are still needed in organisations (UNESCO, 2009).

In the South African context, women in leadership positions are required to deal with numerous challenging situations (Teferra \& Altbeck, 2004). Additionally, in a study conducted by the Commission of Gender Equality (2005), Gouws (2008) reported that 30 per cent of the respondents felt that women are too emotional for leadership positions.

Focusing on gender and organisational behaviour, researchers have argued that: 'male-dominated environments can be difficult for women' (Eagly \& Carli, 2003, p. 15): women seem to receive less favourable evaluations than equivalent male leaders, which increases women's chances of leaving their job or being excluded from male networks. This might link up with the present discourse on authentic leadership and the statement that women often feel inauthentic in maledominated workplaces (Faulkner, 2011).
In terms of everyday organisational behaviour, female leaders are often subjected to discrimination, subtle stereotyping, questions about their competence, sexual harassment and social isolation (Baxter, 2012; Martin, 1992), which can lead to their professional identity being overemphasised (Dezso, Ross \& Uribe, 2012; Mayer, 2011). Recent research has shown that particularly Black women seem to have a strong belief that women can be effective leaders (Booysen \& Nkomo, 2010). Particularly in the South African context, it is suggested that females should not be homogenised across cultures due to the historically disadvantaged situation they have experienced during apartheid in terms of race and gender (Booysen \& Nkomo, 2010).

The positive organisational behaviour approach highlights the positive aspects of individuals coping with their challenges and emphasises the need for more focused and effective application of the positive elements (Luthans, 2002b; Youssef \& Luthans, 2007). A sense of coherence promotes mental health in the workplace (Mayer \& Boness, 2011b) and seems to be strongly connected to various positive organisational behaviour concepts (Kelner, 2001).

Gender and sense of coherence: Focusing on health and well-being, Antonovsky (1987) recognised the fact that individuals can remain healthy, despite the presence of overwhelming stressors. He developed the concept of salutogenesis in response to the question: 'What keeps one healthy?' Salutogenesis includes the concept of the sense of coherence (SOC), a life orientation, which is deemed to be entrenched in an individual's historical and present sociocultural experiences. A SOC develops over time, provided that general resistance resources are repeated, consistent and regular (Rothmann, Jackson \& Kruger, 2003). In contrast, experiences that are unpredictable, uncontrollable and uncertain, lead to a weak SOC and are associated with patterns of declining health (Morrison \& Clift, 2006). A SOC exists out of the sense of comprehensibility (referring to how one understands the world), the sense of manageability (how one copes with challenges) and the sense of meaningfulness (how one is motivated and how one defines one's meaning in life).

Individuals with a high SOC are able to make cognitive sense of the workplace and perceive its stimulation as clear, ordered, structured, consistent and predictable (Mayer, 2011). They perceive their work as consisting of experiences that are bearable and with which they can cope. They see them as challenges that they can cope with by activating personal resources. Furthermore, they can make emotional and motivational sense of work demands and see them as welcome challenges in which they like to invest energies (Antonovsky, 1987; Strümpfer, 1990).

According to Antonovsky (1987), life can be managed and controlled and, therefore, comprehended and experienced as meaningful by both women and men. In his theory, Antonovsky does not focus on gender and SOC, but 
assumes that poor and working class women run the greatest risk of a low SOC, and that class differences are as significant as gender differences.

Previous international research on gender and SOC report higher scores for men than for women (Anson, Paran, Neumann \& Chernichovsky, 1993; Antonovsky \& Sagy, 1985; Larsson \& Kallenberg, 1996; Lindström \& Eriksson 2005). In the South African context, the finding was supported that women score lower in SOC than men in male-dominated work environments (Mayer, 2011; Oosthuizen, 2005). Another South African study, which focused on a parastatal organisation, highlights a significant difference in the average meaningfulness score between men and women, indicating that female managers scored higher in meaningfulness, but lower in total SOC scores in a male-dominated environment (Louw, Mayer \& Baxter, 2012). Volanen (2011), however, emphasises that the impacts on a SOC are gender specific: not having a partner or not being able to use one's skills at work threatens the SOC of men, whilst a lack of social support does the same for women.

\section{Research design \\ Research approach and strategy}

The study followed a mixed-method research approach. It was an inductive single embedded case study based on a phenomenological research paradigm in the epistemological tradition of constructivism (Berger \& Luckmann, 2000) and interpretative hermeneutics (Habermas, 1999). The research design falls into the positive organisational behaviour study frame by being mainly concerned with individual psychological qualities in organisations. At the same time, the research methods at the level of analysis focus on the microlevel of organisations using surveys and qualitative methods (Donaldson \& Ko, 2010; Salkind, 2012; Scholz \& Tietje, 2002). The research is founded on the assumption that realities are constructed through narrations, behaviours and their subjective interpretations in a sociocultural context (Becvar \& Becvar 2006). In order to gain an in-depth qualitative understanding of selected aspects of gender and positive organisational behaviour in the selected organisation, a single-case descriptive mixed-method study approach was used, thereby expanding the depth and richness of the results (Scholz \& Tietje, 2002). The aim is to achieve a holistic understanding of the current environment in which the female leaders function. It focuses on gaining a deeper understanding of the research issue (Cheldelin, Druckman \& Fast, 2003), deep data and thick descriptions (Geertz, 1987). The results were obtained from a single institution, and therefore the generalisability of the results is limited to the scope of the case study.

\section{Research method}

Research setting: The organisation approached for this study is one of Europe's leading German engineering groups (Organisational Paper, 2006a). The organisation has been based in South Africa for several decades and is one of the major global acting engineering groups with the largest sales regions in Southern Africa (Organisational Paper, 2006b, p. 65).

This organisation was selected for the research because of its:

- Global and regional business involvement and standing.

- Comprehensively implemented and managed safety, health and environment (SHE) policies (Organisational Paper, 2008).

- International management profile.

- Willingness to participate.

Entrée and establishing researcher roles: Access to the organisation and to the female leaders at senior management levels in particular, was provided by the human resource management department of the South African headquarters of the organisation. The human resource manager agreed to the research project and provided access to the board of the organisation as well as to the interviewees. The researcher spent several weeks in the organisation to conduct observations on interactions and to communicate with the managers and conduct interviews.

\section{Sampling method}

Natural sampling procedures were implemented by encouraging the entire population of female managers (top, middle and lower management) at the headquarters to participate in the study. In total, 15 of 25 female managers voluntarily agreed to participate in the study.

\section{Data collection methods}

Quantitative: A survey-based research design was used to gather data based on the female leaders' $(N=15)$ perceived sense of coherence. Measurement only took place at a single timestamp. Respondents were requested to complete the survey before the qualitative interview process took place.

Qualitative: Data were obtained by conducting in-depth interviews with the respondents $(N=15)$ regarding their perceptions of sense of coherence and mental health. The interview contained 10 standardised questions with regard to health and well-being, health concepts, health promotion, life orientation, gender and health and healthy organisations, as reflected in the results section. The concepts asked for, such as 'life orientation', were not explained. It was part of the research to identify what aspects female leaders would mention when they were asked about the abovementioned concepts.

Triangulation of data was used by conducting in-depth interviews, observation, and reviewing secondary literature and the organisation's internal documents.

\section{Measuring instrument}

Quantitative: The 29-item Life Orientation Questionnaire (Antonovsky, 1979) was used to determine the participants' sense of coherence in order to support the qualitative data. The questionnaire comprises 29 items and measures SOC 
as represented by comprehensibility, manageability and meaningfulness. According to Antonovsky (1993), the alpha coefficients of questionnaires vary between 0.85 and 0.90 for Western populations. With regard to local applicability, Wissing (2000) confirmed that the questionnaire is reliable in the South African context, with Cronbach alphas being higher than the suggested 0.6 (Nunnally \& Bernstein, 1994). As a result of the small sample size, Cronbach alphas were not calculated for the SOC scale.

Qualitative: In-depth interviews were conducted ranging from 60-120 minutes, depending on the responses and the narration of the interviewee. These interviews were based on predetermined research questions focusing on the issue of research. Observations were made and field notes taken during the research study.

\section{Recording of data}

The in-depth interviews were recorded on dictaphones, stored on a computer and transcribed verbatim.

\section{Data analysis}

Quantitative: Descriptive statistics (through the use of mean comparisons) was used in order to provide context to the qualitative results. It was used to match the SOC scores to the qualitative data in order to enhance the credibility of the qualitative results.

Qualitative: The in-depth interviews were analysed according to the following five-step process of content analysis (Terre Blanche, Durrheim \& Kelly, 2006, pp. 322326): (1) familiarisation and immersion, (2) induction of themes, (3) coding, (4) elaboration and (5) interpretation and checking. The interviews were (re)-constructed by means of content analysis using categorisation and coding, which resulted in the elaboration and interpretation. Categorisation and coding led to the text analysis and recategorisation. Categories resulted in the development of clusters to form themes, which were used to describe the research phenomenon. Data were analysed by using ATLAS.ti. Data gained through observation, field notes and collateral talks contributed to the interpretation of data.

\section{Strategies employed to ensure quality data and ethical considerations}

Regarding the qualitative research findings, qualitative research criteria were considered. As research quality criteria, four major concepts, namely conformability (Terre Blanche et al., 2006), credibility (Poggenpoel, 1998), transferability (Van der Riet \& Durrheim, 2008) and trustworthiness (Gummesson, 2000) were defined. Research ethical guidelines were adhered to throughout the study to ensure the quality of the data. The participants participated voluntarily and each signed an informed consent form. Ethical considerations were approved by both the organisation and research institution.

\section{Findings and results}

In terms of the biographical data of the female leaders in the organisation involved in the study, the following can be highlighted: regarding the age of the participants, one individual was in the age range of 20-30, five in the range $30-40$, seven in the range 40-50 and two in the range 50-60. Out of 110 managers at the headquarters, 25 managers were female; 15 female managers voluntarily agreed to participate in the survey. Ten of the female managers defined themselves as White (seven South African, one German expatriate, one Bulgarian and one Dutch), two as Indian, two as Black and one as mixed-race.

The range of positions held by the participants in the company were as follows: management board member (human resources), quality assurance and safety manager, group training and development specialist, public relations managers, procurement managers, brand image specialist, communication and marketing manager, wellness manager, information technology support manager, credit risk manager; manager group accounting, inventory and supply chain manager and pricing manager.

The following section will be split in terms of the qualitative results and quantitative findings obtained in this study.

\section{Quantitative results}

Sense of coherence in female leaders: The findings (see Table 1) show that out of 15 female leaders in the organisation, five scored the highest in comprehensibility, nine scored the highest in the subscale of manageability and none of the female leaders scored the highest in meaningfulness. Regarding the total scores for the levels of sense of coherence, the Indian woman, who is a leader in the field of finance management, scored the highest in SOC with a score of 189 (Participant 24 [P24]). This score was followed by a Black procurement manager (P10) who scored 180, a Black manager in the health section of the human resource department (P17), followed by a White German/South African senior IT manager (P9). The individual who scored the lowest, with a total score of 89 , was a young Indian woman who was placed in a leading position in finance (P22) in the previous year. She also scored the lowest of all the female leaders for meaningfulness.

TABLE 1: Sense of coherence scores of female leaders.

\begin{tabular}{|c|c|c|c|c|}
\hline \multirow[t]{2}{*}{ Participant } & \multicolumn{3}{|c|}{ Score per subscale } & \multirow{2}{*}{$\begin{array}{l}\text { Total } \\
\text { score }\end{array}$} \\
\hline & Comprehensibility & Manageability & Meaningfulness & \\
\hline $\mathrm{P} 1$ & 60 & 59 & 48 & 167 \\
\hline P2 & 46 & 45 & 37 & 128 \\
\hline P3 & 53 & 53 & 42 & 148 \\
\hline P8 & 52 & 60 & 47 & 159 \\
\hline P9 & 55 & 68 & 55 & 178 \\
\hline P10 & 65 & 60 & 55 & 180 \\
\hline P15 & 56 & 59 & 51 & 166 \\
\hline P17 & 62 & 61 & 47 & 170 \\
\hline P19 & 46 & 60 & 52 & 158 \\
\hline P20 & 50 & 55 & 44 & 149 \\
\hline P21 & 51 & 52 & 44 & 147 \\
\hline P22 & 33 & 34 & 22 & 89 \\
\hline P23 & 47 & 52 & 39 & 138 \\
\hline P24 & 68 & 67 & 54 & 189 \\
\hline P26 & 50 & 44 & 43 & 137 \\
\hline
\end{tabular}


After gaining insight into the SOC scores of the 15 leaders, the following subsections will present the qualitative research findings regarding how the female leaders define their orientation in life, how they connect their mental health to gender in their organisational context and which individual strategies contribute to mental health and positive organisational behaviour in the organisation.

\section{Qualitative findings}

Defining the life orientation that contributes to mental health: Female leaders were interviewed about how their health and well-being contribute to the promotion of a healthy 'life-orientation' (see Table 2).

For seven out of the 15 female leaders, their 'orientation in life' and treating others as they would like to be treated were of major concern. The female IT manager, P9, highlighted, for example:

'If I had to run up one sentence, is with work, is, ah, treat the person the way you want to be treated as. I think that would be, in one sentence, how I feel. Yeah, speak to in the same tone as you wanna be spoken at [laughter].'

Other female leaders (five out of 15) indicated that respect is their main orientation in life. Respecting oneself and others is extremely important to facilitate mental health in the organisation (e.g. P10).

In association with showing respect, another highly appreciated approach to life amongst female leaders is to 'look at the positive side of life'. Another leader (P19) described this in terms of metaphors:

'I come from a positive [emphasis], ah, feel in life. If things are tough, ahm, they give me a perspective on how good other things are. Ahm, and I think it gives one a good contrast and one needs to have dark moments and bright moments and not despair in times that, that things aren't going well, because I think experience tells one that every cloud has a silver lining

TABLE 2: Life orientation of female leaders.

\begin{tabular}{|c|c|c|}
\hline $\begin{array}{l}\text { Number of female } \\
\text { interviewees }\end{array}$ & Category & Interviewee number(s) \\
\hline 7 & $\begin{array}{l}\text { Treat others like you want } \\
\text { to be treated }\end{array}$ & $\mathrm{P} 1, \mathrm{P} 8, \mathrm{P9}, \mathrm{P} 15, \mathrm{P} 19, \mathrm{P} 21, \mathrm{P} 22$ \\
\hline 5 & Respect & $\mathrm{P} 1, \mathrm{P} 10, \mathrm{P} 15, \mathrm{P} 19, \mathrm{P} 22$ \\
\hline 4 & Positive outlook on life & $P 5, P 19, P 20, P 23$ \\
\hline 4 & $\begin{array}{l}\text { Help others or concern for } \\
\text { others }\end{array}$ & $P 2, P 15, P 20, P 22$ \\
\hline 3 & Be principles & P10, P19, P21 \\
\hline 3 & $\begin{array}{l}\text { Be value driven (Know good } \\
\text { from bad) }\end{array}$ & P16, P19, P20 \\
\hline 2 & Be responsible & P15, P17 \\
\hline 2 & Be compassionate & P2, P20 \\
\hline 2 & Work or study hard & P17, P23 \\
\hline 2 & Be religious & P9, P20 \\
\hline 1 & $\begin{array}{l}\text { Enjoy daily things you see } \\
\text { and do }\end{array}$ & P16 \\
\hline 1 & Enjoy new experiences & P5 \\
\hline 1 & Keep the body healthy & P15 \\
\hline 1 & Believe in yourself & P10 \\
\hline 1 & Live for the family & P9 \\
\hline 1 & Balanced life & P15 \\
\hline
\end{tabular}

and, ah, when you get to the other side of the cloud there's a lot more sunshine than darkness. [....] Ah [exclamation] be positive [laughter], be positive, smile, share a smile with those who don't have one, ahm, have fun, ah [...] and try to instil a positiveness in those that are not feeling so positive. I, I get great joy out of, probably my welfare sort of feeling. I like to, to look after people, to nurture them, so in, when times are tough and I have a feeling that people need me I probably become more positive. Ahm, that's my personal strategy.'

By being positive and sharing her positive outlook with others, P19 feels upbeat. She participates actively in becoming mentally healthy by thinking positive thoughts and sharing them with others. Being positive is connected to happiness, smiling as an expression of happiness and fun. Particularly when P19 experiences challenges along the way, she feels positive because, in her opinion, challenges occur to test the individual's ability to manage them. Managing challenges successfully leads to affirmation of the person's ability and experiences of even more positivity once the challenge has been overcome.

In another part of the interview, P19 highlighted the fact that she also believes in respect and in treating every person as you would like to be treated. The social aspect of positive relationships and a positive outlook on life is vital for P19, who works in a leading position in communication and marketing. Some of the other female managers also highlighted the 'concern for others' as a key aspect of staying mentally healthy (P2, P15, P20, P22).

However, parallel to these social factors, selected female leaders also highlighted individual factors that support their well-being in the organisation. These included factors such as 'being principled' (P10, P19, P21), value-driven (knowing good and bad) (P16, P19, P20), being responsible (P15, P17) and being compassionate (P2, P20). Finally, belief (P9, P10, P20), family life (P9), keeping the body healthy (P15), enjoying the day (P16) and leading a balanced life (P15) were also mentioned as essential to maintaining well-being in the organisation.

\section{How are mental health and gender connected in the eyes of the female leaders?}

In terms of mental health and gender, in the in-depth interviews, only three of the 15 female leaders referred to a connection between mental health and gender. Of significance here is the fact that these three female leaders scored the highest on SOC. This shows that the three women connected their mental health to reflecting on gender identity issues whilst reflecting on the organisational behaviour and environment at the same time. These three constructs of interlinking gender and mental health can be explained as follows:

Participant 10, a Sotho-speaking procurement manager, mentioned at the beginning of the interview in the context of health-creating strategies that the organisation is fairly male dominated:

'[...] well the culture, ahm, I can say it's, it's male dominated, that's how they, the environment is [...] Yeah, well, with male, 
but [laughter] not much also there, but of, of course I think it's because of the industry, the image of the industry, yeah. You find most ladies on, on the support part of the business and the rest it's, it's male. Yeah.'

This procurement manager, P10, recognises the fact that she works in a male-dominated environment and explains that 'male domination' is part of the image of the industry she works in. She seems to be proud that she, as a woman, is in a leading position, whilst the majority of women working in this male-dominated environment are in the support part of the business. Most of the higher positions are occupied by male managers. By acknowledging this, P10 is aware of her exceptional view about women in the organisation. However, her mental health does not seem to be much influenced by the male domination. If it is, then it seems that she experiences this in a positive way, since she is consciousness that she has a successful career as a top manager. Regarding mental health, she appears to adhere to her health promotion strategies of 'respecting herself and others' and particularly 'believing in yourself' as a person, instead of as a woman. Hence for her, 'being a person' is more important than 'being a woman'.

For P23, an Indian credit risk manager, gender is merely one aspect of identity.

'If you're referring to, ahm, other genders or other cultures or whatever, I think its important to actually know [emphasis] who you, who you're dealing with, ahm, cause sometimes you can also understand some, ahm, the way people react and, and, and sort of be, have empathy for how they react and then you don't take it personally.'

Personhood, thus, again appears to be more significant to this leader than gender identification: only if you know a person, can you develop empathy and understanding for this person and their reactions. Gender may be one aspect that is necessary to understand other people; however, in P23's opinion, it is not the main aspect.

Participant 9 experiences gender in the organisation from a totally different perspective from that of P10 and P23. In her narration, she highlights the European and South African perspective on gender, gender roles and gender behaviour:

'I have a, a Black, ah, female and a Black male employee and I mean in, ah, in their culture woman's not supposed to really do exactly what the man does but they have the same job and he feels since she's got the same job she should also carry like a man and there are sometimes, ah, you get the gender problems you have, but we, we, we've made a bit of more, ahm, rules like, okay, if she does this what do you want to do, you know, that type of thing and divided it more what they [emphasis] feel, themselves, so okay I've made up my mind I want her to do this, let's do that.'

'I think it was just more a gender problem, [...] female's thinking male should work more or carry more than females, you know. In, ahm [...] the only thing is, ahm [...] except maybe in Germany, because in Germany I feel, I've felt and the way my mom brought us up is the more equal to gender, man. [...] So maybe there is a little bit with the culture that, ah, European women seem to grab a bit more, I do it myself man, I don't need to wait for anybody.'
In her narration, P9 explains that women in South Africa are more passive than women in Europe. According to her observation, women in Europe have a 'do it yourself' approach, whilst women in South Africa usually wait for a man to do the job. To P9, this is a pity, because she feels that women should be able to look after themselves and become more independent and active. She contends that men in the South African context are more caring towards women in terms of offering seats to them or opening doors and fulfilling their 'traditional' gender roles. It is thus obvious that P19 prefers the approach of the active and self-reliant woman, which she recognises in herself, in her family and in the German and/or European culture. However, this approach goes hand in hand with her family and religionoriented values in terms of remaining healthy and balanced. For her, a balanced life is also related to equality in gender (roles), respect for one another, religion and a respectful mutual treatment.

For all the three high-scoring female leaders, gender is a key aspect of their mental health, which they tend to view as positive instead of negative in terms of their own gender identity. They interpret their gender roles in a maledominated environment as positive or neutral, and not negative at all. All three of them seem to be self-aware and have a balanced view of gender and their role as female leaders in this environment.

\section{What strategies do female leaders use to contribute to positive organisational behaviour in terms of constructing a 'healthy organisation'?}

The following categories (see Table 3) show that female leaders focus on their individual health and personal responsibility to stay healthy and thereby contribute to a healthy organisation.

For the participants (see Table 3), actions that keep them physically fit are of paramount importance, such as maintaining a healthy diet, doing physical exercise and being (bodily and mentally) energetic. The physical health strategies are followed by mentally implemented health

TABLE 3: Contribution to a healthy organisational environment.

\begin{tabular}{|c|c|c|}
\hline $\begin{array}{l}\text { Number of female } \\
\text { interviewees }\end{array}$ & Category & Interviewee number(s) \\
\hline 8 & Healthy nutrition & $\mathrm{P} 1, \mathrm{P} 5, \mathrm{P} 9, \mathrm{P} 10, \mathrm{P} 15, \mathrm{P} 16, \mathrm{P} 17, \mathrm{P} 23$ \\
\hline 7 & Physical exercise & $\mathrm{P} 5, \mathrm{P} 9, \mathrm{P} 15, \mathrm{P} 16, \mathrm{P} 17, \mathrm{P} 20, \mathrm{P} 23$ \\
\hline 5 & Be energetic & $\mathrm{P} 2, \mathrm{P9}, \mathrm{P} 17, \mathrm{P} 19, \mathrm{P} 22$ \\
\hline 5 & Balanced life & $\mathrm{P} 1, \mathrm{P} 5, \mathrm{P} 10, \mathrm{P} 17, \mathrm{P} 22$ \\
\hline 5 & $\begin{array}{l}\text { Make people happy, be } \\
\text { happy }\end{array}$ & $\mathrm{P} 1, \mathrm{P} 16, \mathrm{P} 17, \mathrm{P} 19, \mathrm{P} 22$ \\
\hline 4 & Mediate, relax & $\mathrm{P} 1, \mathrm{P} 2, \mathrm{P} 10, \mathrm{P} 17$ \\
\hline 3 & $\begin{array}{l}\text { Be empathetic and } \\
\text { support others }\end{array}$ & P19, P22, P23 \\
\hline 3 & $\begin{array}{l}\text { Keep time for leisure or } \\
\text { take breaks }\end{array}$ & $\mathrm{P} 1, \mathrm{P} 5, \mathrm{P} 22$ \\
\hline 3 & $\begin{array}{l}\text { Have time with kids or } \\
\text { grandchildren }\end{array}$ & P5, P9, P16 \\
\hline 3 & $\begin{array}{l}\text { Manage problems or } \\
\text { deadlines }\end{array}$ & P10, P15, P17 \\
\hline 2 & Be sane or think positively & P5, P16 \\
\hline 1 & Make music & P20 \\
\hline
\end{tabular}


strategies, such as balancing life, being happy and making others happy, supporting others, being empathetic and thinking positively. However, practical approaches to health are being with children and grandchildren, enjoying leisure time and taking breaks. Health strategies such as relaxation techniques, meditation, music making, developing positive thinking styles and managing work-related problems and deadlines were also emphasised by the participants.

Participant 15, for example, stated that unfulfilled needs, such as healthy nutrition, food and sleep impact on a person's (mental) health:

'I do think that, that health does plays a part and your personality, if you, you know, if you want to say, I mean if you're not eating properly, ahm, if you're not doing exercise, if you're not sleeping, then all of those are gonna affect you as, as a person. Ahm, and a lot of the time not in a good way.'

Once again, the concept of personhood plays a vital part in building (mental) health for P15, a brand image specialist who is South African with a Polish family background. Though she expressed her ideas in positive sentences, she also emphasised the negative effects of a person not focusing on healthy nutrition and exercise. This could indicate that the underlying motivators for eating healthily and doing exercise are not negative, but instead attributes of the development of personal health and well-being.

Participant 22 was a young Indian leader who had been with the organisation less than a year. Focusing on her responses to what strategies she uses to keep healthy, she responded as follows:

'I try and tell myself to be happy all the time, be grateful for what I have. Ahm, I feel [laughter] maybe this is cultural as well, I just feel what you give out is what you get back and if I'm gonna make somebody's day horrible somebody's gonna make my day horrible. And you have [emphasis] your odd days. Ahm, but it's, it's how [emphasis] you treat everybody, that's very important. Ahm, how, that's how I stay healthy, and so. I always don't take anything personally and I try and do the best in any situation. If I can't do anything about it I always leave [emphasis] work at work and come the next day with a fresh mind and say, okay, how will I sort this out. And normally prioritisation works well, if there's many tasks [laughter]. No [...] I think, I watch lots of, ahm, motivational DVDs, listen to them in my car, read lots of motivational books. Ahm, yes [exclamation] I, I enjoy keeping myself motivated, it's just something I enjoy doing. Being grateful for the little things is very important. And nothing else health-wise, ah, I have no time for gym [laughter].'

This female leader keeps herself healthy through motivational strategies, such as watching motivational DVDs and listening to motivational CDs. She needs external motivation to keep her motivated, which reassures her repeatedly of herself and her inner strength. This is also evident in the first sentences in which she states: 'I try to tell myself to be happy at all times'. By stating how she tries to be happy and grateful, her insecurity becomes visible. At the same time, she depends a lot on her social relationships and on her beliefs that the way she treats others also impacts on her. Her health promotion strategies are therefore linked to external sources. However, at the same time, her individual resources, such as effective prioritisation, always working towards the best and enjoying her leisure time, keep this leader healthy.

\section{Discussion}

The aim of this study was to evaluate the perspectives of female leaders about (creating) mental health and experiencing a sense of coherence in a selected South African organisation. The aim of the study was thus to promote an understanding of gender-related subjective perceptions of female leaders in this context. This study was conducted in the context of positive organisational behaviour and focused on the psychological capacities of the participants (Luthans, 2002a). In particular, the authors viewed gender as a selected diversity category in positive organisational psychology and the study, therefore, contributes to building the genderrelated positive organisational literature (Ramarajan \& Thomas, 2010). It should help to fill the void of positive organisational behaviour and gender research highlighted by Sandelands (2002) and also aims to contribute to improvements in experiences of health and well-being in the organisation (Youssef \& Luthans, 2007) by firstly researching the concepts of life orientation, health strategies, sense of coherence and gender.

Female leaders in the selected organisation showed a wide variance from 89-189 in total scores. The highest scores were achieved by the Black and Indian female leaders in the organisation. This finding supports the literature in emphasising the strength of Black women in leadership (Booysen \& Nkomo, 2010), here with regard to mental health and well-being. At the same time, the findings show that, particularly in the South African context, women should not be homogenised across cultures due to the varied historical and social situations in terms of race and gender (Booysen \& Nkomo, 2010).

The women who had joined the organisation recently (6-12 months before) scored lower than the women who had been at the organisation for longer than 12 months. Most of the participants scored high on comprehensibility, followed by manageability. However, they scored low on meaningfulness; none of the participants scored high on meaningfulness.. This might be due to the fact that comprehensibility and manageability are more important and predominant for managers in their daily routine than the construction of meaningfulness. This result underpins the findings of former studies (Louw et al., 2012).

As emphasised in the literature (Geißler et al., 2003), the narrations of life orientation and mental health show that personal resources and positive perceptions of health and well-being contribute to the well-being and health of individuals. This supports the findings of previous positive psychology studies (Seligman, 2011; Seligman \& Csikszentimihalyi, 2000). The female leaders in the organisation indicated that their life orientation and, thus, their mental health were socially determined. Nearly half of 
the participants in the research (seven) mentioned that the positive treatment of others around them forms the basis of their life orientation; this was followed by (mutual) respect (five) and concern for others (four). This was followed by individual factors that contribute to their main life orientation and health, such as a having a positive outlook on life (four), being principled (three), being value-driven (three), being responsible, compassionate and religious (two) and being hardworking (two).

According to Eagly and Carli (2003), female leadership is on the rise, and women in this study seem to be aware of their extraordinary position in this male-dominated environment. However, they do not ascribe the challenging situations within the organisation to gender differences, as highlighted in the literature (Teferra \& Altbeck, 2004). The female leaders in this study do not pay much attention to mental health and its connection to gender and do not overemphasise their professional identity (Deszo, Ross \& Uribe, 2012). Only three women - those who scored high on SOC - mentioned health in the context of gender, which shows a general approach to self-reflection. These women define themselves rather as 'a person' than as 'a woman', although they are self-conscious about their extraordinary leadership position as women within the organisation. However, gender does not seem to impact strongly on them and, where it does, only in a positive way. Gender is seen as one part of the identity and is not highlighted as a particular category of mental health.

The female leaders in this study contribute to creating a healthy organisation by emphasising their individual responsibilities towards keeping healthy such as following a healthy diet (eight), engaging in physical exercise (seven), being energetic (five) and balancing their life (five). In their opinion, a healthy organisation is also built by means of the following: happiness (five), mutual support (four), relaxation techniques (four) leisure time (three) and spending time with one's children and grandchildren (three), as well as sticking to deadlines, thinking positively and using relaxation techniques (two) and listening to music (one). This research thus supports the current literature which highlights the fact that female leaders include physical, social, psychological and emotional factors in their view of 'healthy organisations' (Mayer \& Boness, 2011a) and see themselves as a whole person (Davies et al., 2003).

These findings have generated new insights on creating and managing healthy organisations within the South African context (Feldt, Kivimäki, Rantala \& Tolvanen, 2004), particularly with regard to gender.

\section{Limitations and recommendations}

Although this study provides an interesting context for understanding gender-related leadership behaviours, it does have limitations. It is a multi-method single embedded case study, founded on a relatively small set of quantitative data. The findings are 'subjective data' and present emic perspectives of selected individuals. Hence, the data are not necessarily generalisable, and follow-up studies would be required to support the findings in similar and different organisational and national contexts.

This study shows that many open questions on gender, sense of coherence and mental health in the positive organisational behaviour framework need to be responded to. Hence, it is suggested that future research in South Africa should focus on:

- Creating theoretical knowledge through rethinking gender categories and their implications in post-modern, transcultural organisations.

- Exploring female perspectives on positive organisational behaviour in more detail and comparing them with indepth male perspectives in a positive organisational behaviour context.

- Conducting further mixed-method studies in various cultural and organisational settings (e.g. femaledominated organisational settings), focusing on the positive organisational behaviour of male and female leaders, fully evaluating the similarities and differences between health-related strategies and behaviours and focusing on statistically relevant data.

- Researching the connection between gender, culture and the impact of apartheid and present gender and culturally determined roles within organisations.

\section{Conclusion}

In conclusion, conscious support of the positive organisational behaviour and a health-strengthening and health-conscious organisational awareness and responsibility should be created with regard to the practical implications for the organisation. Female leaders should thus be encouraged to focus on creating a healthy organisation, which is constructed not only through the social and individual aspects of the women themselves, but also through organisational health promotion campaigns. In practical terms, organisations should become more aware of and conscious about issues of gender and health with regard to:

- Recognising that thoughtfulness about gender issues at work and how they affect organisational coherence and health.

- Creating meaningfulness in the organisation and particularly for female leaders.

- Promoting holistic leadership approaches, highlighting the importance of balancing family and work life.

- Promoting psychological counselling and training to developing SOC and gender consciousness amongst female leaders.

- Offering training courses on health, well-being and the development of salutogenesis, particularly with regard to female leaders in male-dominated environments.

- Exploring work behaviours of female leaders in the context of their culture and cultural values within postapartheid South Africa.

These organisational activities, could positively support and increase mental health in female leaders by connecting 
directly to their health concepts and health-promoting strategies, thereby contributing to a general increase in the health and well-being of managers.

\section{Acknowledgements Competing interest}

The authors declare that they have no financial or personal relationship(s) that may have inappropriately influenced them in writing this article.

\section{Authors' contributions}

C-H.M. (University of South Africa) and L.E.v.Z. (University of South Africa) contributed equally to the writing of this article.

\section{References}

Afifi, M. (2007). Gender differences in mental health. Singapore Medical Journal, $48(5), 385-391$.

Alvesson, M., \& Billing, Y.D. (1992). Gender and organisation: Towards a differentiated understanding. Organisation Studies, 13(12), 73-103. http://dx.doi. understanding. Organisation St
org/10.1177/017084069201300107

Amanatullah, E.T., \& Morris, M.W. (2010). Negotiating gender roles: Gender differences in assertive negotiating are mediated by women's fear of backlash and attenuated when negotiating on behalf of others. Journal of Personality and Social Psychology, 98, 256-257. http://dx.doi.org/10.1037/a0017094

Anson, O., Paran, E., Neuman, L., \& Chernichovsky, D. (1993). Gender differences in health perceptions and their predictors. Social Science and Medicine, 36(1), 419427. http://dx.doi.org/10.1016/0277-9536(93)90404-R

Antonovsky, A. (1979). Health, stress and coping. San Francisco, CA: Jossey-Bass.

Antonovsky, A. (1987). Unraveling the mystery of health: how people manage stress and stay well. San Francisco, CA: Jossey-Bass.

Antonovsky, A. (1993). Complexity, conflict, chaos, coherence, coercion and civility. Social Science Medicine, 37, 969-981. http://dx.doi.org/10.1016/02779536(93)90427-6

Antonovsky, H., \& Sagy, S. (1985). The development of a sense of coherence and its impact on responses to stress situations. Journal of Social Psychology, 126, 213-225.

Barkhuizen, N., \& Rothmann, S. (2004). Burnout of academic staff in a higher education institution. Paper presented at the 2nd South African Work Wellness Conference, 25-26 March 2004, Potchefstroom University, South Africa.

Baxter, J. (2012). Feminist research. The encyclopedia of applied linguistics, 17(2), 107-116.

Becvar, D.S., \& Becvar, R.J. 2006. Family therapy: a systemic integration. (6th edn.). Boston, MA: Allyn \& Bacon.

Berger, P.L., \& Luckmann, T. (2000) Die gesellschaftliche Konstruktion der Wirklichkeit. Eine Theorie der Wissenssoziologie [The social construction of reality. A theory of the sociology of knowledge]. (17th edn.). Frankfurt, Germany: Fischer.

Bez, Y., \& Emhan, A. (2011). Psychological distress in women working in banks. Asia-Pacific Psychiatry, 3, 145-150. http://dx.doi.org/10.1111/j.17585872.2011.00133.x

Booysen, L. \& Nkomo, S.M. (2010). Gender role stereotypes and requisite management characteristics: the case of South Africa. Genderand Management: An international Journal, 25(4), 285-300. http://dx.doi.org/10.1108/17542411011048164

Brinkmann, R.D. (1993). Personalpflege - Gesundheit, wohlbefinden und arbeitszufriedenheit als strategische grössen im personalmanagement [Personal care - Health, well-being and job satisfaction as strategic variables in personnel management]. Heidelberg, Germany: Sauer-Verlag.

Carless, S.A. (1998). Gender differences in transformational leadership: an examination of superior, leader, and subordinate perspectives. Sex Roles, 39(11) 887-902. http://dx.doi.org/10.1023/A:1018880706172

Cheldelin, S., Druckman, D. \& Fast, C. (2003). Conflict from analysis to intervention. New York, NY: Continuum.

Chugh, D., \& Brief, A.P. (2008). Introduction: where the sweet spot is: Study diversity in organizations. In A.P. Brief, Diversity at work (pp. 1-2). New York, NY: Cambridge University Press. http://dx.doi.org/10.1017/CBO9780511753725.003

Commission on Gender Equality. (2005). National gender opinion survey Johannesburg, South Africa.

Davies, J., Davies, R., \& Heacock, S. (2003). A wellness program for faculty. Educationa Leadership, 7, 68-70

Dezso, C.L., Ross, D.G., \& Uribe, J.N. (2013). Why are there so few women top managers? A large-sample empirical study of the antecedents of female participation in top management. Social Science Research Network, 11(1). participation in top management. Social Science Research Network, 11(1).
Retrieved February 17, 2013, from http://ssrn.com/abstract=2200579 http:// dx.doi.org/10.2139/ssrn.2200579
Donaldson, S.I., \& Ko, I. (2010). Positive organisational psychology, behavior, and scholarship: A review of the emerging literature and evidence
base. The Journal of Positive Psychology, 5(3), 177-191. http://dx.doi. base. The Journal of Positive
org/10.1080/17439761003790930

Eagly, A.H., \& Carli, L.L. (2003). The female leadership advantage: an evaluation of the evidence. The Leadership Quarterly, 14, 807-883. http://dx.doi.org/10.1016/j. leaqua.2003.09.004

Eagly, A.H., Johannesen-Schmit, M.C., \& Van Engen, M.L. (2003). Transformational, transactional, and laissez-faire leadership styles: a meta-analysis comparing women and men. Psychological Bulletin, 129(4), 569-591. http://dx.doi. org/10.1037/0033-2909.129.4.569, PMid:12848221

Faulkner, W. (2011). Gender (in)authenticity, belonging and identity work in engineering. Brussels Economic Review, 54(2/3), 277-293.

Feldt, T., Kivimäki, M., Rantala, A., \& Tolvanen, A. (2004). Sense of coherence and work characteristics: a cross-lagged structural equation model among managers.
Journal of Occupational and Organisational Psychology, 77, 323-342. http:// Journal of Occupational and Organisation
dx.doi.org/10.1348/0963179041752655

Geertz, C. (1987). Dichte beschreibung. Beiträge zum verstehen kultureller systeme [Thick description. Contributions to the understanding of cultural systems]. Frankfurt, Germany: Suhrkamp.

Geißler, H., Bökenheide, T., Geißler-Gruber, B., Schlükes, H., \& Rinninsland, G. (2003) der anerkennende erfahrungsaustausch. Das neue Instrument für die führung [The acknowledging of experience. The new instrument for leadership]. Frankfurt, Germany \& New York, NY: Campus Verlag.

Gouws, A. (2008). Obstacles for women in leadership positions: A case of South Africa, Signs: Journal of Women in Culture and Society, 34(1), 21-27. http://dx.doi. org/10.1086/588486

Grant, A.M., \& Campbell, E.M. (2007). Doing harm, doing good, being well and burning out: The interactions of perceived prosocial and antisocial impact in service work. Journal of Occupational and Organisational Psychology, 80, 665-691. http:// dx.doi.org/10.1348/096317906X169553

Gummesson, D.E. (2000). Qualitative methods in management research. (2nd edn.). Thousand Oaks, CA: Sage.

Habermas, J. (1999). Theorie des kommunikativen handelns [Theory of communicative action]. (3rd edn.). Frankfurt, Germany: Suhrkamp.

Kelner, S. (2001). Authentic sights and authentic narrations on Taglit. Paper presented at the 33rd Annual Meeting of the Association for Jewish Studies, 16 December 2001, Washington, DC

Larsson, G., \& Kallenberg, K. (1996). Sense of coherence, socio-economic conditions and health: interrelationship in a nation-wide Swedish sample. European Journal of Public Health, 6, 175-180. http://dx.doi.org/10.1093/eurpub/6.3.175

Lawthom, R. (1999). Using the ' $F$ ' word in organizational psychology: Foundations for critical feminist research. Annual review of Critical Psychology, 1, 65-78.

Legare, C.H., \& Gelman, S.A. (2009). South African children's understanding of AIDS and flu: Investigating conceptual understanding of cause treatment and prevention. Journal of Cognition and Culture, 9, 357-370. http://dx.doi.org/10.11 63/156770909X12518536414457, PMid:20631923

Lindström, B., \& Eriksson, M. (2005). Salutogenesis. Journal of Epidemiology and Community Health, 59(6), 440-442. http://dx.doi.org/10.1136/jech.2005.034777, PMid:15911636

Louw, L., Mayer, C.-H., \& Baxter, J. (2012). Exploring the relationship between valueand life-orientation and job satisfaction. Acta Commercii, 12, 45-67.

Luthans, F. (2002a). The need for and meaning of positive organisation behavior Journal of Organisational Behavior, 23, 695-706. http://dx.doi.org/10.1002/ job.165

Luthans, F. (2002b). Positive organisational behavior: developing and managing psychological strengths. Academy of Management Executive, 16, 57-72. http:// dx.doi.org/10.5465/AME.2002.6640181

Lyubomirsky, S. (2013). The myth of happiness: What should make you happy but doesn't, what shouldn't make you happy but does, what happiness really is - and isn't. New York, NY: Penguin.

Macik-Frey, M., Quick, J.D., Quick, J.C., \& Nelson, D.L. (2009). Occupational health psychology: From preventive medicine to psychologically healthy workplaces. In A.G. Antoniou, C.L. Cooper, G.P. Chrousos, C.D. Spielberger, \& M.W. Eysenck (Eds.), Handbook of managerial behaviour and occupational health, pp. 3-19). (Eds.), Handbook of managerial behaviour and occupational health, pp. 3-19).
Cheltenham, UK: Edward Elgar. http://dx.doi.org/10.4337/9781848447219.00008

Maddux, J.E., \& Winstead, B.E. (2011). Psychopathology: foundations for a contemporary understanding. New York, NY: LEA.

Martin, P.Y. (1992). Gender, interaction, and inequality in organisations. In C.L. Ridgeway (Ed.), Gender, interaction, and inequality, pp. 208-231. New York, NY: Springer-Verlag. http://dx.doi.org/10.1017/S0020818300033245

Mayer, C.-H. (2008). Managing conflict across cultures, values and identities. Münster, Germany: Waxmann.

Mayer, C.-H. (2011). The meaning of sense of coherence in transcultural management. Münster, Germany: Waxmann.

Mayer, C.-H., \& Boness, C. (2011a). Concepts of health and well-being in managers: An organisational study. International Journal of Qualitative Studies on Health and Well-being, 6(4). Retrieved January 23, 2013, from http://www.ijqhw.net/index. php/qhw/article/view/7143/12896

Mayer, C.-H. \& Boness, C. (2011b). Interventions to promoting sense of coherence and transcultural competences in educational contexts. International Review of Psychiatry, 23(6), 516-525. http://dx.doi.org/10.3109/09540261.2011.637906

Mayer, C.-H., Louw, L., \& Louw, T. (2010). Sense of coherence and organisational commitment: A case study in a selected South African par-statel. Competitive
Paper, 22nd Annual Conference of the Southern Africa Institute for Management Scientists (SAIMS), 12-15 September 2010, Mpekweni Beach Resort, South Africa. 
Mendes, F., \& Stander, M.W. (2011). Positive organisation: the role of leader behaviou in work engagement and retention. South African Journal of Industrial Psychology, $37(1), 3$ pages.

Morrison, I., \& Clift, S.M. (2006). Mental health promotion through supported further education: The value of Antonovsky's salutogenic model of health. Healt Education, 106(5), 365-380. http://dx.doi.org/10.1108/09654280610685956

Nunnally, J.C., \& Bernstein, I.H. (1994). Psychometric theory. (3rd edn.). New York. NY: McGraw-Hill.

Oosthuizen, J. (2005). The relationship between stress and salutogenic functioning amongst employees in a state owned enterprise. Unpublished master's dissertation, University of the Western Cape, South Africa.

Oplatka, I. (2002). Women principles and the concept of burnout: an alternative voice? International Journal of Leadership in Education: Theory and Practice, 5(3) 211-226. http://dx.doi.org/10.1080/136031200112873

Organisational Paper. (2006a). Annual report [organisation]. Retrieved August 24, 2009, from http://www.[organisation].co.za

Organisational Paper. (2006b). Company profile [organisation] 2005. Retrieved November 24, 2009, from http://www.[organisation].co.za.

Organisational Paper. (2008). Safety, health and environmental policy. Internal document PZ/HRP/Vm, [Organisation]

Pillay, K. (2008). Sense of coherence, work engagement and organisationa commitment within an automotive development institute. Retrieved February 20 2013, from http://uir.unisa.ac.za/dspace/bitstream/10500/3168/1/dissertation pillay_k.pdf

Poggenpoel, M. (1998). Data analysis in qualitative research. In A.S. de Vos (Ed.), Research on grass roots: a primer for the caring professions, pp. 78-134. Pretoria, South Africa: Van Schaik.

Ramarajan, L., \& Thomas, D. (2010). A positive approach to studying diversity in organisations. Working paper 11-024. Harvard Business Press. Retrieved February 20, 2013, from http://hbswk.hbs.edu/item/6524.html

Rosenblatt, Z., Talmud, I., \& Ruvio, A. (1999). A gender-based framework of the experience of job-insecurity and its effects on work attitudes. European Journal of Work and Organisational Psychology, 8(2), 197-217. http://dx.doi. Journal of Work and Organisation
org/10.1080/135943299398320

Rothmann, S., \& Cilliers, F.V.N. (2007). Present challenges and some critical issues for research in industrial/organisational psychology in South Africa. South African Journal of Industrial Psychology, 33(1), 8-17.

Rothmann, S., \& Rothmann, S. (2010). Factors associated with employee engagement in South Africa. South African Journal of Industrial Psychology, 36(2), 12 pages.

Rothmann, S., Jackson, L.T.B., \& Kruger, M.M. (2003). Burnout and job stress in a local government: The moderating effect on sense of coherence. South African Journa of Industrial Psychology, 29(4), 52-60.

Rothmann, S., Steyn, L.J., \& Mostert, K. (2005). Job stress, sense of coherence and work wellness in an electricity supply organisation. South African Journal of Business Management, 36(1), 55-63.

Ruiz-Cantero, M., Vives-Cases, C., Artazcoz, L., Delgado, A., del Mar Gracia Calvente, M., Miqueo, C. et al. (2007). A framework to analyse gender bias in epidemiological research. Journal of Epidemiology and Community Health, 61(2), ii46-ii53. http:// dx.doi.org/10.1136/jech.2007.062034

Sachs-Ericsson, N., \& Ciarlo, J. (2010). Gender, social roles, and mental health: An epidemiological perspective. Sex Roles, 43(9), 605-628.

Salkind, N.J. (2012). Exploring research. (8th edn.). Salt River, NJ: Pearson.

Sandelands, L.E. (2002). Male and female in organisational behaviour. Journal of Organisational Behaviour, 23, 149-165. http://dx.doi.org/10.1002/job.134

Scholz, R.W. \& Tietje, O. (2002). Embedded case study methods: integrating quantitative and qualitative knowledge. London, UK: Sage.

Seligman, M.E.P. (2011). Flourish: a visionary new understanding of happiness and well-being. New York, NY: Free Press.

Seligman, M.E.P., \& Csikszentimihalyi, M. (2000). Positive psychology: An introduction. American Psychologist, 55, 5-14. http://dx.doi.org/10.1037/0003-066X.55.1.5
South Africa. (1993). Occupational Health and Safety Act, No. 85 of 1993. Pretoria, South Africa: Government Printer.

South African Department of Labour. (2004). Safety and health at work commemoration. Retrieved May 5, 2008, from http://www.labour.gov.za/media/ statement.jsp

Stellman, J.M. (Ed.). (1998). Encyclopaedia of occupational health and safety. (4th edn.). Geneva, Switzerland: International Labour Office.

Strümpfer, D.J.W. (1990). Salutogenesis: A new paradigm. South African Journal of Psychology, 20, 45-52. http://dx.doi.org/10.1177/008124639002000406

Teferra, D., \& Altbach, P.G. (2004). African higher education: challenges for the 21st century. Higher Educ

Terre Blanche, M., Durrheim, K., \& Kelly, K. (2006). First steps in qualitative data analysis. In M. Terre Blanche, K. Durrheim, \& D. Painter (Eds.), Research in practice: Applied methods for the social sciences, pp. 321-344. Cape Town, South Africa: University of Cape Town.

Thomas, D.A., \& Gabarro, J.J. (1999). Breaking through: the making of minority executives in corporate America. Boston, MA: Harvard Business School.

Thomas, D.A. (2001). The truth about mentoring minorities: race matters. Harvard Business Review, 79(4), 98-112.

Thomas, D.A. (2004). Diversity as strategy. Harvard Business Review, 82(9), 77-89.

UNESCO. (2009). Learning, research and innovation. Retrieved November 13, 2012, from http://www.unesco.org/en/wche2009/sub-themes/equity-access-quality

Van der Riet, M., \& Durrheim, K. (2008). Putting design into practice: writing and evaluating research proposals. In M.T. Terre Blanche, K. Durrheim, \& D. Painter (Eds.), Research in practice: Applied methods for the social sciences, pp. 80-112. Cape Town, South Africa: University of Cape Town.

Van Zyl, L.E., \& Rothmann, S. (2012). Beyond smiling: The development and evaluation of a positive psychological intervention aimed at student happiness. Journal of Psychology in Africa, 22(3), 78-102.

Van Zyl, L.E., \& Stander, M.W. (2013). The strengths based coaching model. In J. White, R. Motching, \& M. Lux (Eds.), Theory and practice of the person-centered approach: Interconnections beyond psychotherapy, pp. 132-149. New York, NY: Springer.

Van Zyl, L., Deacon, E., \& Rothmann, S. (2010). Towards happiness: work-role fit, meaningfulness and engagement of industrial/organisational psychologists in South Africa. South African Journal of Industrial Psychology, 36(1), 71-88.

Volanen, S.-M. (2011). Sense of coherence. determinants and consequences. Academic dissertation. Helsinki, Finland: Hjelt Institute, Department of Public Health, Faculty of Medicine, University of Helsinki.

Wissing, M.P. (2000). Wellness: Construct clarification and a framework for future research and practice. Keynote address at the 1st South African Wellness Conference, 2-5 May, Port Elizabeth.

World Health Organisation. (1948). Preamble to the constitution of the World Health Organisation. Adapted by the International Health Conference, New York, June 1946, signed on 22 July 1946 by the representatives of 61 states and entered into force on 07 April 1948 (official records of the World Health Organisation, no. 2, p. 100).

World Health Organisation. (2003). Gender, health and tobacco. Geneva, Switzerland: Department of Gender and Women's Health.

Wrzesniewski, A. (2003). Finding positive meaning at work. In K. Cameron, J.E. Dutton, \& R.E. Quinn (Eds.), Positive organisational scholarship, pp. 296-308. San Francisco, CA: Berrett-Koehler.

Wrzesniewski, A., Dutton, J., \& Debebe, G. (2003). Interpersonal sense making and the meaning of work. Research in Organisational Behavior, 25, 95-135. http://dx.doi. org/10.1016/S0191-3085(03)25003-6

Wrzesniewski, A., \& Tosti, J. (2005). Career as a calling. In J.H. Greenhaus, \& G.A Callanan (Eds.), Encyclopaedia of career development, pp. 38-49. Thousand Oaks, CA: Sage.

Youssef, C.M., \& Luthans, F. (2007). Positive organisational behaviour in the workplace: The impact of hope, optimism, and resilience. Journal of Management, 33, 774800. http://dx.doi.org/10.1177/0149206307305562 